\title{
Environmental Behavior among Higher Education Students
}

\author{
Sara Sousa ${ }^{1}$, Elisabete Correia ${ }^{2}$, Joana Leite $^{3}$, Clara Viseu ${ }^{4}$ \\ ${ }^{1}$ Coimbra Business School ISCAC, Polytechnic Institute of Coimbra and CERNAS \\ Quinta Agrícola - Bencanta 3040-316 Coimbra, Portugal \\ ssousa@iscac.pt \\ ${ }^{2}$ Coimbra Business School | ISCAC, Polytechnic Institute of Coimbra and CEFAGE, \\ Quinta Agrícola - Bencanta 3040-316 Coimbra, Portugal \\ ecorreia@iscac.pt \\ ${ }^{3}$ Coimbra Business School ISCAC, Polytechnic Institute of Coimbra and CMUC \\ Quinta Agrícola - Bencanta 3040-316 Coimbra, Portugal \\ jleite@iscac.pt \\ ${ }^{4}$ Coimbra Business School | ISCAC, Polytechnic Institute of Coimbra and CICF \\ Quinta Agrícola - Bencanta 3040-316 Coimbra, Portugal \\ cviseu@iscac.pt
}

\section{Extended Abstract}

In the last decades, we have been witnessing to an unprecedented worsening of environmental problems worldwide, namely: greenhouse gas emissions, deforestation, pollution, climate change, among many others. The mitigation of these environmental aggressions requires that, in a joint effort, all countries undertake deep restructuring of their production and consumption economic systems and comply with their environmental governance obligations, so that economic development is achieved in harmony with environmental protection [1,2].

Under a dictatorial regime for almost half a century, Portugal had a late awakening to environmental issues, reaching the 1970s with considerable socioeconomic backwardness compared to other European countries. The 1974 revolution started a process of intense change, particularly pronounced after the Portugal's accession to the European Union in 1986 and, from then on, national environmental policies have been shaped under the European Union`s directives [3]. Recently, on 5 October 2016, with the main aim of strengthening the global response to some of the most serious environmental problems, the European Union Member States, including Portugal, ratified the Paris Climate Agreement and pledged to reduce considerable greenhouse gas emissions in the next years [4,5]. This environmental commitment requires a deep change in the population's behavior. In this context, educational institutions have a key role, being responsible for the education and training of future leaders, decision makers, intellectuals and employers [6,7].

This study aims to investigate the environmental behavior of a particular set of the Portuguese population: the higher education students. Another goal of this research is to deepen the importance of environmental knowledge and attitudes in the individuals` environmental behavior. To achieve the proposed objectives, we designed and distributed online questionnaires among the students of a public higher education institution in Portugal and obtained 371 valid responses. The Cronbach's alpha for the three dimensions analyzed are over 0.7 , which is in line with literature. The exploratory data analysis results revealed that: students have a high level of knowledge about the main current environmental problems; with regard to attitudes, the responses obtained allow us to conclude that the majority of students reveal to be sensible to the main environmental issues and recognize the necessity to protect both animals and nature; most students manifest a clear positive attitude towards the environment; students also consider to be well informed on the main environmental issues and the main sources are television and social networks; students report practicing with high regularity the following environmentally friendly activities: use of paper, water and energy in strictly necessary quantities; recycle; use of paper or fabric bags as an alternative to plastic bags; and refuse to use single-use plastic objects. Non-parametric inferential tests showed that there are no differences in most items that compose the environmental knowledge taking into account the gender, studies' degree, age, cohabitation and household's income. The same conclusions for environmental behavior. With 
regards to attitudes, there are differences between men and women and the results suggest that women have a more positive attitude towards the environment.

\section{References}

[1] Jianping, L., Minrong, L., Jinnan, W., Jianjian, L., Hongwen, S. and Maoxing, H., "Global Environmental Issues and Human Wellbeing”, In: Jianping L., Minrong L., Jinnan W., Jianjian L., Hongwen S., Maoxing H. (eds) "Report on Global Environmental Competitiveness" (2013), Current Chinese Economic Report Series, Springer, Berlin, Heidelberg, 2014.

[2] UNEP, Sustainable Consumption and Production - A Handbook for Policymakers, Global Edition, United Nations Environment Programme, 2015.

[3] Carvalho, A., Schmidt, L., Santos, F.D. and Delicado, A., "Climate change research and policy in Portugal", WIREs Climate Change, 2013.

[4] EC, The Environmental Implementation Review 2019 - Country Report Portugal, European Commission, Brussels, 2019.

[5] MATE, Roadmap for Carbon Neutrality 2050 (RNC2050) - Long-Term Strategy for Carbon Neutrality of the Portuguese Economy by 2050. Ministério do Ambiente e Transição Energética da República Portuguesa, 2019.

[6] Labanauskis, R., and Ginevičius, R., Role of stakeholders leading to development of higher education services, Engineering Management in Production and Services, 2017, 9(3), pp. 63-75.

[7] Aleixo, A.M., Azeiteiro, U.M. and Leal, S., "Are the sustainable development goals being implemented in the Portuguese higher education formative offer?", International Journal of Sustainability in Higher Education, 2020, Vol. 21(2), pp. 336-352. 